\title{
The presence of pulses within a meal can alter fat-soluble vitamin bioavailability
}

Marielle Margier ${ }^{1}$, Tiffany, Antoine ${ }^{1}$, Aurélie Siriaco ${ }^{1}$, Marion Nowicki ${ }^{1}$, Charlotte Halimi ${ }^{1}$, Matthieu

Maillot $^{3}$, Stéphane Georgé ${ }^{2}$ Emmanuelle Reboul ${ }^{1 * *}$

${ }^{1}$ INRA, INSERM, Aix Marseille Univ, C2VN, Marseille, France.

${ }^{2}$ CTCPA, Avignon.

${ }^{3}$ MS-Nutrition, Marseille, France

**Address correspondence to: Emmanuelle Reboul, UMR 1062 INSERM/1260 INRA/Aix-

Marseille University, Faculté de Médecine, 27 boulevard Jean-Moulin, 13385 Marseille

Cedex 5 FRANCE. E-mail: Emmanuelle.Reboul@univ-amu.fr. Office telephone number: +33

(0)491324278

Abbreviations: DMEM (Dulbecco's Modified Eagle's), PBS (Phosphate Buffered Saline), SR-BI

(Scavenger Receptor class B type I), NPC1L1 (NPC1 transporter like 1)

Key words: legumes, carotenoids, fibers, phytates, saponins, tannins, bioaccessibility, intestinal absorption

Received: DECEMBER 04, 2018; Revised: FEBRUARY 08, 2019; Accepted: MARCH 06, 2019

This article has been accepted for publication and undergone full peer review but has not been through the copyediting, typesetting, pagination and proofreading process, which may lead to differences between this version and the Version of Record. Please cite this article as doi: 10.1002/mnfr.201801323.

This article is protected by copyright. All rights reserved. 


\section{Abstract}

Scope: It is widely advised to increase pulse consumption. However, pulses are rich in molecules displaying lipid-lowering properties, including fibers, phytates, saponins and tannins. We thus explored the effects of pulses on fat-soluble vitamin bioavailability.

Methods: We assessed vitamin A ( $\beta$-carotene and retinyl-palmitate), vitamin E ( $\alpha$-tocopherol), vitamin $\mathrm{D}$ (cholecalciferol) and vitamin $\mathrm{K}$ (phylloquinone) bioaccessibility, i.e. micellarization after in vitro digestion of meals containing either potatoes (control), household-cooked or canned pulses. The obtained mixed micelles were delivered to Caco-2 cells to evaluate vitamin uptake. We then specifically assessed the impact of fibers, phytates, saponins and tannins on both phylloquinone (used as a model vitamin) bioaccessibility and uptake.

Results: The presence of pulses significantly decreased both vitamin bioaccessibility (up to $-65 \%$ for $\beta$-carotene, $-69 \%$ for retinyl-palmitate, $-45 \%$ for cholecalciferol, $-53 \%$ for $\alpha$-tocopherol and $-67 \%$ for phylloquinone) and uptake (-40\% for retinyl-palmitate, $-67 \%$ for cholecalciferol, $-50 \%$ for $\alpha$ tocopherol and $-57 \%$ for phylloquinone). Effects on bioaccessibility, but not on uptake, were dependent on pulse cooking method. Phylloquinone bioaccessibility was specifically impacted by saponins, tannins and fibers while its uptake was impacted by saponins, fibers and phytates.

Conclusion: Pulses can alter fat-soluble micronutrient bioavailability. Pulses should thus be cooked appropriately and consumed within micronutrient-rich meals.

This article is protected by copyright. All rights reserved. 
The presence of prepared pulses within a meal could alter both the bioaccessibility and the uptake of fat-soluble vitamins. This effect was dependent on pulse type and/or on pulse cooking method, likely because pulse contents in molecules with lipid-lowering properties such as fibers, phytates, saponins and tannins were different between these conditions.

Experiments with purified fibers, phytates, saponins and tannins strongly suggested that these compounds were responsible for the decrease of fat-soluble vitamin bioavailability.

Our results thus underline the importance of consuming pulses within micronutrient-rich meals/ recipes.

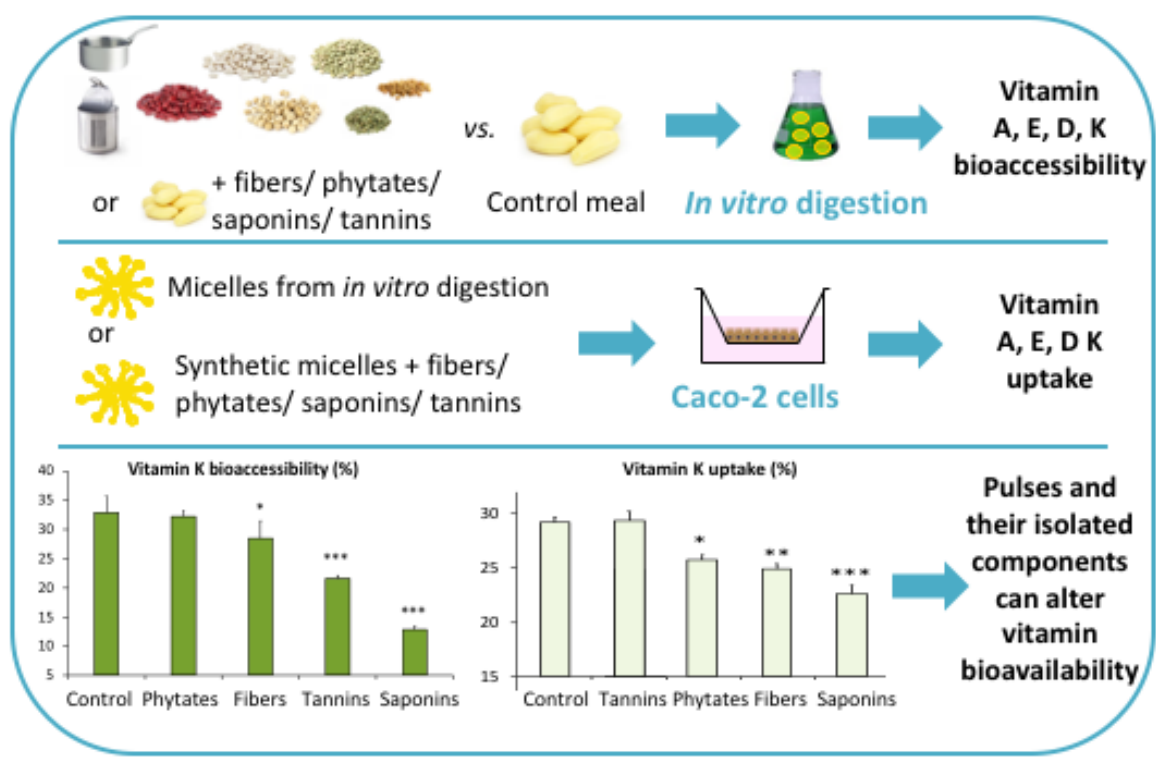

This article is protected by copyright. All rights reserved. 


\section{Introduction}

Fat-soluble vitamins (i.e. vitamin A, D, E and K) are essential molecules playing key roles in the development and the perenniality of our organism. The occurrence of fat-soluble vitamin deficiencies is a major public health issue in developing countries, as these deficiencies can lead to blindness and infections [1], rickets [2], neurologic defects [3], as well as hemorrhagic diseases of the newborn [4]. Fat-soluble vitamin (principally vitamin D and E) sub-deficiencies and/ or insufficient intakes have also been described in Western countries [5, 6]. The correlation between these subdeficiencies and the growing incidence of chronic pathologies including cardiovascular, neurodegenerative and bone pathologies is presently widely explored because several studies reported a causative association $[7,8]$.

Extensive investigation over the past decades focused on the factors regulating fat-soluble vitamin absorption. Indeed, even if these vitamins are brought in adequate amounts in the diet, their health effects depend on their bioavailability, which can be modulated by interactions with other meal components. For example, it has been showed that fat could act as an effector of fat-soluble micronutrient absorption, while polyphenols, phytosterols or fibers could alter their bioavailability (reviewed in [9-11]).

Besides, for the growing human population in a world with limited resources, one vital challenge today is the ability to make diets sustainable for all. Pulses may constitute a part of the solution. Indeed, additionally to their environmental benefits [12], they are a good source of proteins, fibers, micronutrients and bioactive phytochemicals [13]. It has also been shown that regular consumption of pulses can lead to decreased plasma cholesterol and triglyceride levels [14], suggesting an impact on lipid absorption and/or metabolism. This impact is likely due to pulse fiber content [15], but other pulse bioactive compounds such as phytates, saponins or polyphenols may also play important roles in this phenomenon [13]. There is little clear data on the effects of phytates on lipid digestionabsorption process. However, a recent study in chickens showed that phytates could affect lipase 
activity and lipid metabolism [16]. In addition, saponins have often been described as anti-obesity compounds [17], notably by inhibiting the activity of pancreatic lipase [18]. Saponins may also limit the micellar incorporation of cholesterol [19]. The lipid-lowering properties of pulses constitute another reason to promote their consumption. However, these data suggest that pulses can also have an impact on fat-soluble vitamin absorption. Interestingly, the cooking method can modulate the bioactive compound content of pulses [20]. Pulse cooking method may consequently modulate the putative effect of pulses on fat-soluble vitamin absorption.

The aim of our study was thus to i) assess the impact of pulses (kidney beans, white beans, chickpeas, green/ brown lentils and flageolets) and their preparation modes (home cooking vs. canning) on the bioavailability of vitamin A (retinyl palmitate and its precursor: $\beta$-carotene), D (cholecalciferol), E ( $\alpha$-tocopherol) and K (phylloquinone); and ii) to decipher the molecular mechanisms underlying these effects.

This article is protected by copyright. All rights reserved. 


\section{Materials and methods}

\section{Chemicals}

Retinyl palmitate, cholecalciferol, $\alpha$-tocopherol, phylloquinone and $\beta$-carotene (all > 95\% pure), as well as 2-oleoyl-1-palmitoyl-sn-glycero-3-phosphocholine (phosphatidylcholine), 1-palmitoyl-snglycero-3-phosphocholine (lysophosphatidylcholine), monoolein, free cholesterol, oleic acid, sodium taurocholate, fibers (cellulose), phytates (phytic acid sodium salt hydrate), saponins (purified quillaia saponins) and tannins (grape seeds oligomeric proanthocyanidins) were purchased from Sigma Aldrich. Refined olive oil was generously provided by Dr Marie-Josèphe Amiot (UMR Moisa, Montpellier, France). Minced beef (with 5\% of fat) and potatoes were purchased from a local supermarket (Casino, France). Kidney beans (Phaseolus Vulgaris L.), white beans (Phaseolus Vulgaris L.), chickpeas (Cicer Arietinum), green lentils (Lens culinaris M.), brown lentils (Lens culinaris M.) and flageolets (Phaseolus vulgaris L.) were purchased at CIACAM society (Vitrolles, France). Note that the pulses used in this study were from the same lots than the pulses fully characterized previously [20].

\section{Pulse preparation}

Pulses were either cooked following a household method (Table 1) or canned (Table 2) according to standard protocols [20]. To respect traditional eating habits, green lentils and flageolets were prepared following the household-cooking method while brown lentils were canned. Kidney beans, white beans and chickpeas were prepared with both methods, allowing to compare the effect of the cooking method on fat-soluble vitamin bioavailability.

This article is protected by copyright. All rights reserved. 
Fiber, phytate, saponin and tannin measurements in pulses and pureed potatoes

Fibers, phytates, saponins and tannins had previously been assayed in the different prepared pulses [20]. Fibers, phytates, saponins and tannins from potatoes were assayed following the same methods.

\section{In vitro digestion experiment}

The meals used in the first set of in vitro digestion experiments were made of $1.2 \mathrm{~g}$ of pan-cooked minced beef meat, $200 \mu \mathrm{L}$ of refined olive oil and either $6.7 \mathrm{~g}$ of pureed potatoes (control) or $6.7 \mathrm{~g}$ of cooked pulses. The meals used in the second set of experiments were made of $1.2 \mathrm{~g}$ of minced beef meat, $200 \mu \mathrm{L}$ of refined olive oil and $6.7 \mathrm{~g}$ of potatoes, and were supplemented with purified cellulose $(0.7 \mathrm{mg})$, phytates $(42.5 \mathrm{mg})$, saponins $(6 \mathrm{mg})$ or tannins $(0.4 \mathrm{mg})$. These amounts were specifically chosen to mimic on average those brought in the test meals by prepared pulses ([20], Table 3). Beef and refined olive oil brought minor amounts of fat-soluble vitamins to the meal, which has no consequence on the interpretation of the data as these two ingredients were present in all conditions. Each test meal was supplemented with $200 \mathrm{ng}$ of fat-soluble vitamins dissolved in the refined olive oil. The in vitro digestion experiment was conducted as previously described [21, 22]. The final mixture representing the digesta was centrifuged $\left(2500 \mathrm{~g}, 1 \mathrm{~h}, 10^{\circ} \mathrm{C}\right)$ to separate the aqueous fraction containing the mixed micelles. Aliquots of digestas and mixed micelles were taken and stored at $-80^{\circ} \mathrm{C}$ under a nitrogen atmosphere until analysis. Bioaccessibility was calculated as the percentage of vitamin recovered in mixed micelles divided by the amount of vitamin recovered in the digesta at the end of the digestion. Note that micellar vitamin A, initially provided in the form of retinyl palmitate, was mainly recovered as retinol.

This article is protected by copyright. All rights reserved. 


\title{
Fat-soluble vitamin absorption by intestinal cells in culture
}

\author{
Preparation of micelles from in vitro digestion
}

According to preliminary cytotoxicity tests, fat-soluble vitamin micelles obtained from in vitro digestions were diluted in DMEM (1:7; vol:vol).

\section{Preparation of synthetic mixed micelles enriched in vitamin $\mathrm{K}$}

Synthetic mixed micelles were prepared as previously described [23]. Briefly, appropriate volumes of phosphatidylcholine, lysophosphatidylcholine, monoolein, cholesterol, oleic acid and vitamin $\mathrm{K}$ stock solutions were transferred to glass bottles to obtain the following final concentrations: $0.04 \mathrm{mM}$, $0.16 \mathrm{mM}, 0.3 \mathrm{mM}, 0.1 \mathrm{mM}, 0.5 \mathrm{mM}$ and $5 \mu \mathrm{M}$, respectively. Stock solution solvents were carefully evaporated under nitrogen. Dried residue was solubilized in DMEM containing $5 \mathrm{mM}$ taurocholate and vigorously mixed by 25 watt sonication (Branson 250W sonifier, Osi) for $3 \mathrm{~min}$. The mixtures obtained were sterilized and filtered by passing them through a presterilized $0.22 \mu \mathrm{m}$ filter. The concentration of vitamin $\mathrm{K}$ in the micellar solutions was measured before each experiment. The day of the experiments, mixed micelles were supplemented or not in cellulose, phytates, saponins and/or tannins, at the following concentrations: $212 \mu \mathrm{g} / \mathrm{mL}, 30 \mu \mathrm{g} / \mathrm{mL}, 2 \mu \mathrm{g} / \mathrm{mL}$ and $3.5 \mathrm{mg} / \mathrm{mL}$, respectively, to be in accordance with the mean levels putatively recovered in micelles after pulse digestion (Table 3 [20]).

\section{Cell experiments}

Caco-2 clone TC7 cells were cultured as previously described [24]. Twelves houses prior each experiment, serum-free complete medium were used in apical and basolateral chamber. At the beginning of the experiment, the apical side received either fat-soluble vitamin micelles obtained from in vitro digestions diluted in DMEM, or synthetic mixed micelles enriched in vitamin $\mathrm{K}$ (used as a model vitamin). The basolateral side received serum free complete medium. Cells were incubated $1 \mathrm{~h}$ at $37^{\circ} \mathrm{C}$ with the mixed micelles. Cells were then washed with $0.5 \mathrm{~mL}$ PBS to eliminated adsorbed 
fat-soluble vitamins, scraped and collected in $0.5 \mathrm{~mL}$ ice-cold PBS. Absorbed vitamin was calculated as the percentage of the amount of vitamin recovered in cells divided by the total amount of vitamin delivered to the cells (i.e. vitamin found in the medium plus vitamin remaining in the cells at the end of the experiment). Note that due to the short incubation time (1h), vitamin A was recovered in cells as retinol only. All the samples were stored at $-80^{\circ} \mathrm{C}$ until analysis.

\section{Fat-soluble vitamin extraction}

The internal standards were retinyl acetate for samples containing retinyl palmitate and vitamin $D_{3}$, echinenone for samples containing vitamin $\mathrm{K}$, tocopheryl nicotinate for samples containing vitamin $\mathrm{E}$ and apo- $8^{\prime}$-carotenal for samples containing $\beta$-carotene, respectively. Samples were extracted as previously described [25]. The dried extract was dissolved in $200 \mu \mathrm{L}$ of methanol-dichloromethane (65:35; vol:vol). A final volume of $50 \mu \mathrm{L}$ for micelle samples, $20 \mu \mathrm{L}$ for digesta samples, $180 \mu \mathrm{L}$ for the cellular sample were used for HPLC analysis. The fat-soluble vitamins were separated as previously described [26]. All molecules were identified by retention time compared with standards by UVvisible detection.

\section{Statistical analysis}

For all groups, data were expressed as mean \pm SEM. Statistical analyses were performed using SPSS (SPSS Inc., Chicago, USA). Prior to ANOVA (fixed-effects models), data were tested for equality of variances. The distribution of all dependent variables was graphically checked and was considered as normal. Tukey's test was used as a post-hoc test for pairwise comparisons. A principal Component Analysis (PCA) was conducted on all samples (including replicates) and all variables to analyze the relationship between the presence of fibers/ phytates/saponins/tannins and fat-soluble vitamin bioaccessibility and uptake.

This article is protected by copyright. All rights reserved. 


\section{Results}

Potatoe and pulse composition in fibers, phytates, saponins and tannins.

We previously showed that $100 \mathrm{~g}$ of drained cooked pulses contained $3.8 \mathrm{~g}$ to $13.8 \mathrm{~g}$ of dietary fibers, 386 to $714 \mathrm{mg}$ of phytates, $99 \mathrm{mg}$ to $175 \mathrm{mg}$ of saponins and 1.8 to $16.6 \mathrm{mg}$ of tannins, depending on both pulse type and pulse cooking method [20]. In comparison, we showed that 100g of cooked potatoes contained $2.2 \pm 0.0 \mathrm{~g}$ of dietary fibers, $141.5 \pm 19.6 \mathrm{mg}$ of phytates, $32.3 \pm 1.3$ mg of saponins, and no tannins. These results are summarized in Table 3.

\section{Bioaccessibility of fat-soluble vitamins is decreased in the presence of legumes and this effect is modulated by the cooking method.}

The bioaccessibility of the different fat-soluble vitamins were significantly different from each other within the control meal: vitamin $\mathrm{E}(\approx 41 \%)>$ vitamin $\mathrm{D}(\approx 37 \%)>$ vitamin $\mathrm{K}(\approx 28 \%)>$ retinyl palmitate $(\approx 24 \%)>\beta$-carotene $(\approx 12 \%)$ (Figure 1$)$.

In most of the experiments, the bioaccessibility of fat-soluble vitamins was impaired in the presence of household pulses compared to the control meal. This decreased was dependent on pulse types and on fat-soluble vitamins. For instance, the decrease in retinyl palmitate bioaccessibility ranged from $43 \%$ in the presence of flageolets $(p=0.042)$ to $64 \%$ in the presence of white beans $(p=0.001)$. The bioaccessibility of $\beta$-carotene was decreased from $42 \%$ in presence of white beans $(p=0.122)$ to $65 \%$ in presence of kidney beans $(p=0.004)$. The bioaccessibility of vitamin $D$ was decreased by $34 \%$ and $45 \%$ in the presence of chickpeas $(p=0.03)$ and lentils $(p=0.002)$, respectively. Similarly, the bioaccessibility of vitamin E was significantly decreased from $45 \%$ in presence of kidney beans $(p=0.005)$ to $50 \%$ in presence of flageolets $(p=0.001)$. Finally, the decrease in vitamin $K$

This article is protected by copyright. All rights reserved. 
bioaccessibility was decreased from $47 \%$ in presence of flageolets $(p=0.015)$ to $67 \%$ in presence of chickpeas $(p=0.001)$.

Interestingly, in some experiments, results showed that canned pulses were less deleterious than household cooked pulses. For example, the bioaccessibility of $\beta$-carotene was higher in the presence of canned chickpeas compared to household-cooked chickpeas $(+111 \%, p=0.023)$. The bioaccessibility of retiol/ retinyl palmitate was also more important in presence of canned white beans than in the presence of household-cooked white beans $(+68.4 \%, p=0.05)$. Finally, vitamin $\mathrm{K}$ bioaccessibility was also increased by $78.4 \%$ in the presence of canned white beans compared to household-cooked white beans $(p=0.05)$.

Fat-soluble vitamin uptake by Caco-2 cells is decreased in the presence of micelles from in vitro digestion of test meals containing pulses compared to control micelles.

The micelles obtained from the in vitro digestion of the test meals containing either potatoes or prepared pulses were then incubated on Caco-2 cells monolayers after dilution in cell culture media. The uptake of the different fat-soluble vitamins after $1 \mathrm{~h}$ of incubation was significantly different from each other within the control meal: vitamin $A(\approx 15 \%)>$ vitamin $E(\approx 11 \%)>$ vitamin $D(\approx 10 \%)>$ vitamin $\mathrm{K}(\approx 4 \%)>\beta$-carotene $(\approx 1 \%)$ (Figure 2$)$.

The presence of micelles from in vitro digestion of meals containing pulses decreased the uptake of fat-soluble vitamins, but not that of $\beta$-carotene, compared to control micelles $(p<0.05)$. The uptake of preformed vitamin A was significantly decreased by $-39.8 \%$ in the presence of micelles isolated from household-cooked white bean in vitro digestion $(p=0.018)$. The uptake of vitamin $D$ was decreased from $-26.3 \%$ in the presence of micelles from digested meals containing flageolets $(p=0.012)$ to $-66.7 \%$ in the presence of micelles from digested meals containing chickpeas $(p=0.01)$. The uptake of vitamin E was significantly decreased by $-34.4 \%$ in the presence of micelles isolated This article is protected by copyright. All rights reserved. 
from canned kidney bean in vitro digestion $(\mathrm{p}=0.001)$. The uptake of vitamin $\mathrm{K}$ was also decreased by $-47.3 \%$ to $-56.7 \%$ in the presence of micelles from digested meals containing kidney beans $(p=0.034)$ or lentils $(p=0.007)$ compared to the control micelles.

Conversely to what was observed for bioaccessibility, pulse cooking method had no clear effect on fat-soluble vitamins uptake.

Fat-soluble vitamin bioaccessibility and uptake are negatively correlated to the presence of fibers, phytates, saponins or tannins

The first and the second principal components of the PCA drove $41.3 \%$ and $15.5 \%$ of the total variance, respectively. Based on the first axe, PCA showed that the presence of phytates, saponins, tannins and fibers were inversely correlated to the bioaccessibility and uptake of all vitamins, and especially both the bioaccessibility and the uptake of vitamin D, E and K, as well as the bioaccessibility of vitamin A (retinyl palmitate) (Figure 3A). On the first axe, potatoes (low in fibers, phytates, saponins and tannins) were opposed to all pulses (Figure 3B). Based on the second axe, PCA showed that the presence of fibers was inversely correlated to $\beta$-carotene bioaccessiblility and uptake, and to retinol uptake; and that the presence of tannins was inversely linked to vitamin $D$ bioaccessibility and uptake and to vitamin $\mathrm{K}$ bioaccessiblity.

We thus performed further experiments using purified fibers, phytates, saponins and tannins to confirm their effects of fat-soluble vitamin bioavailability.

\section{Vitamin $\mathrm{K}$ bioaccessibility is decreased in the presence of fibers, tannins and saponins.}

We specifically assessed the impact of fibers, phytates, saponins and tannins on the bioaccessibility of vitamin $\mathrm{K}$ (used as a model vitamin). 
As shown in Figure 4, the addition of pulse compounds (saponins, tannins and fibers) in a control meal significantly decreased the bioaccessibility of vitamin K. Saponins were the most deleterious, with a reduction in vitamin $\mathrm{K}$ bioaccessibility of $60.9 \%(\mathrm{p}<0.0001)$. This reduction was less important in presence of tannins and fibers $(-34.4 \%, p=0.0002$ and $-13.4 \%, p=0.037$ respectively). Finally, the bioaccessibility of vitamin $\mathrm{K}$ was not decreased in the presence of phytates.

Vitamin K uptake by Caco-2 cells is decreased in the presence of fibers, phytates, saponins and tannins, but these effects are not additive.

The impact of fibers, phytates, saponins and tannins, alone or in combination, on vitamin $\mathrm{K}$ uptake (used as a model vitamin) by Caco-2 cells was finally evaluated (Figure 5).

\section{- Impact of one compound (fibers or phytates or saponins or tannins)}

Vitamin K uptake was significantly decreased when Caco-2 cells were incubated with synthetic mixed micelles containing fibers or phytates or saponins. Our results showed that saponins had the most deleterious effect: vitamin $\mathrm{K}$ uptake was decreased by $22.5 \%$ compared to the control condition $(p<0.001)$. The presence of fibers and phytates in synthetic mixed micelles also decreased vitamin $\mathrm{K}$ uptake by $14.8 \%(p=0.01)$ and $11.9 \%(p=0.05)$, respectively. Tannins alone had no effect on vitamin $\mathrm{K}$ uptake compared to the control condition.

- Impact of two compounds

The presence of two pulse compounds in synthetic mixed micelles was less deleterious than the presence of a single compound. This decrease varies from $2.1 \%$ to $18.0 \%$ depending on the conditions. Tannin + saponins decreased vitamin K uptake by $18.0 \%$ compared with the control condition $(p=0.0005)$. Similarly, fibers + saponins decreased vitamin $K$ uptake by $14.5 \%(p=0.013)$. In the presence of tannins, fibers did not impact vitamin K uptake anymore. Similarly, the addition of 
phytates to another compound (saponins or tannins or fibers) in the synthetic mixed micelles did not induced a reduction of vitamin $\mathrm{K}$ uptake compared to the control condition.

- Impact of three compounds

The presence of saponins in a combination of 3 pulse compounds appeared to reduce vitamin $\mathrm{K}$ uptake. Indeed, saponins + tannins + phytates and saponins + tannins + fibers decreased vitamin K uptake by $18.2 \%(p=0.0009)$ and $15.3 \%(p=0.0063)$, respectively, compared to the control.

Conversely, phytates + fibers + tannins and phytates + fibers + saponins conditions had no effect on vitamin K uptake.

- Impact of four compounds:

Finally, the combination of 4 pulses compounds (fibers, phytates, saponins and tannins) significantly decreased vitamin $\mathrm{K}$ uptake $(-14.5 \% ; \mathrm{p}=0.013)$.

This article is protected by copyright. All rights reserved. 


\section{Discussion}

Pulses components are acknowledged to impair mineral bioavailability [27], as well as to reduce lipid absorption [14]. However, no data are available on the effect of pulses on fat-soluble vitamin and carotenoid digestion-absorption. This study thus aimed at assessing and deciphering the effect of pulses on the 2 main steps governing fat-soluble vitamin bioavailability, i.e. their transfer to mixed micelles (bioaccessibility) and their entry into the intestinal cell (uptake by the enterocyte). Bioaccessibility was evaluated using an in vitro digestion model, while uptake by enterocyte was evaluated using Caco-2 cells in culture.

In vitro digestions were first performed with test meals containing meat and refined olive oil, and completed with either potatoes or pulses as a side dish. In most cases, the presence of pulses (kidney beans, white beans, chickpeas, green or brown lentils, flageolets) within a test meal reduced fat-soluble vitamin and carotenoid bioaccessibility (up to - $65 \%$ for $\beta$-carotene, $-69 \%$ for retinylpalmitate, $-45 \%$ for vitamin $D,-53 \%$ for vitamin $E$ and $-67 \%$ for vitamin $K$ ) compared to a test meal containing potatoes. Different pulse components can be responsible for this effect. PCA analysis showed that fibers, phytates, saponins and tannins from pulses were associated to this negative effect for most of the vitamins. Interestingly, in some case, this negative effect was less important when canned pulses were used compared to paired household-cooked pulses. This can be related to the fact that canned pulses presented a different composition than household-cooked pulses - and in particular less fibers, less phytic acid and sometimes less tannins, due to an increased leaching of water-soluble compounds into the broth during canning process [20].

To further explore the specific effect of each compound, we then conducted in vitro digestions with test meals containing potatoes and supplemented with either purified cellulose, phytates, saponins or tannins, in amounts representing those measured on average in cooked pulses [20]. These in vitro 
digestions were performed with vitamin $\mathrm{K}$ as a model vitamin, as vitamin $\mathrm{K}$ behavior was shown to statistically represent most of the other vitamins (data not shown).

Cellulose was chosen as a fiber model because it is a major fiber in pulses, representing about one half of total dietary fiber in different legume species [28]. It has previously been shown that dietary fibers could bind micellar component such as bile salts, phospholipids or cholesterol in vitro [29], and that fibers could impact on the absorption of some carotenoids but not that of vitamin E [30]. In our study, we found a significant but modest effect of cellulose on vitamin $\mathrm{K}$ bioaccessibility. This confirms that fiber effect on fat-soluble vitamin bioaccessibility is likely moderate.

The second pulse component that can impact on fat-soluble bioaccessibility is phytic acid, due to its potential ability to inhibit lipase activity in the pancreas or small intestine of broilers fed with a high phytate diet [16]. However, when added to a meal containing meat and potatoes, phytates did not reduce vitamin $\mathrm{K}$ bioaccessibility. This lack of effect may be due to potential interaction of phytates with meal proteins during the gastric digestion step [31], which would limit phytate interactions with lipases.

The third compound that could explain this effect is saponins. Indeed, saponins were shown to inhibit the in vitro activity of the pancreatic lipase, and a diet enriched in 35 to $75 \mathrm{mg}$ of saponins / $\mathrm{kg}$ increased triglyceride outputs in rat feces [18]. Our data showed that saponins were the compounds with the higher inhibitory effect on vitamin K bioacessibility. We suggest that this effect is linked to their ability to limit the incorporation of lipids such as cholesterol into mixed micelles [19].

Finally, the last compounds that could explain the inhibitory effect of pulses are tannins. The addition of tannins at fairly low concentrations in the test meal was sufficient to shown a significant reduction of vitamin K bioaccessibility. This inhibitory effect is likely due to an interaction of tannins with pancreatic lipase [32, 33].

This article is protected by copyright. All rights reserved. 
We then explored the effect of pulses on fat-soluble vitamin uptake by differentiated Caco- 2 cell monolayers. This popular enterocyte-like cell model has previously been used widely to investigate fat-soluble vitamin absorption [34-37]. The presence of pulse components in micelles isolated from in vitro digestions altered fat-soluble vitamin uptake $(-40 \%$ for retinyl-palmitate, $-67 \%$ for vitamin $D$, $-50 \%$ for vitamin $\mathrm{E}$ and $-57 \%$ for vitamin $\mathrm{K}$ ). This effect was independent of the cooking method.

We showed in a previous work that micellar fatty acids could impact on vitamin D absorption by modifying mixed micelle physicochemical properties. In particular, fatty acid micellar composition could modulate the size and the electric charge of mixed micelles [38], which in turn impacted on micelle ability to bind the extracellular loop of membrane transporters involved in vitamin D intestinal uptake [39]. In this study, the presence of potatoes vs different cooked pulses in the test meal did not induce any change in the size and electric charge of the micelles obtained from in vitro digestions (data not shown). The observed inhibitory effect on fat-soluble vitamin uptake was thus likely due to the presence of specific pulse compounds in either the extramicellar or the micellar phase.

PCA analysis highlighted that fat-soluble vitamin uptake was also negatively associated with fibers, phytates, saponins and tannins. To confirm these associations and specifically address the effect of each compound on fat-soluble vitamin uptake process by the enterocytes, we assessed the uptake by Caco- 2 cells of micellar vitamin $\mathrm{K}$ (used a s a model vitamin) in the absence or presence of these purified pulse compounds. We used vitamin K-rich synthetic mixed micelles supplemented with pulse compounds and not micelles from in vitro digestion to better control purified compound concentrations. The compounds were added alone or in combination in concentrations mimicking those theoretically found in the micellar phase after pulse digestion. Our results showed a deleterious effect of those compounds on fat-soluble vitamin uptake as follows: saponins > fibers > phytates.

This article is protected by copyright. All rights reserved. 
The strong effect of saponins on vitamin K uptake is not surprising. Indeed, a diet enriched in saponins (0.9\%) induced an increased cholesterol excretion in chicks, as well as a defect in vitamin A and $\mathrm{E}$ absorption [40]. Moreover saponins were shown to inhibit carrier-mediated nutrient transport in enterocytes [41]. Saponins may thus interact with fat-soluble vitamin transporters such as the Scavenger Receptor Class B type I (SR-BI) or the NPC1-like 1 transporter (NPC1L1), that are ubiquitous fat-soluble micronutrient transporters [11]. The effect of fibers is likely due to their ability to bind micellar lipids [29], as mentioned above. The effect of phytates at the enterocyte levels was unexpected and require further investigations to identify the underlying mechanisms. Finally, tannins had no effects on vitamin $\mathrm{K}$ absorption. We showed in previous studies that polyphenols could inhibit fat-soluble vitamin and carotenoid bioavailability. In particular, naringenin was shown to inhibit vitamin E [42] and lutein [43] absorption. Additionally, olive oil polyphenols, and especially pinoresinol, also decreased vitamin D intestinal absorption in rats and Caco-2 cells [24]. The lack of effect of tannins in this study may be due to the low concentration used to mimic tannin concentration in pulses. It can also be due to a lack of interactions of tannins with membrane transporters. Indeed, these proteins are usually highly glycosylated [44, 45], which may partly protect them against a complexation with tannins.

Interestingly, the effects of the different compounds were not additive. For instance, the presence of fibers + phytate or fibers + tannins, showed no effect on vitamin K uptake, while fibers or phytates alone were deleterious. This highlight the fact that the compounds can probably interact with each other, which has already been described for fibers and polyphenols [46]. Finally, it worth to mention that the presence of saponins induces a significant decrease in vitamin $\mathrm{K}$ uptake in $6 / 7$ conditions, showing that saponins are likely very potent inhibitors of fat-soluble micronutrient uptake.

After being taken up by the enterocytes, fat-soluble vitamins are incorporated into chylomicrons to be released to the lymph. Further investigations are needed to determine whether pulse components can modulate this last step of fat-soluble vitamin absorption process as well. 
Overall, our results show for the first time that the presence of pulses within a meal can decrease fat-soluble vitamin and carotenoid bioavailability, by impairing both their bioaccessibility and their uptake by intestinal cells. These effects are likely due to the presence of compounds responsible for the lipid-lowering effect of pulses, i.e. fibers, phytates, saponins and tannins. Further investigations are needed to i) verify that the specific effects of these compounds observed on vitamin $\mathrm{K}$ bioavailability can be extended to other fat-soluble vitamins, ii) fully understand the molecular mechanisms underlying such effects, and iii) identify the interactions modulating the effects of these compounds, including when pulses are cooked together with meat and oil and not just added as a side dish afterwards. Moreover, as pulse cooking method can modulate their fiber and phytate contents [20], which can in turn have an impact on fat-soluble vitamin bioavailability, additional research is required to set up household or industrial preparation processes limiting the presence of unwanted compounds without altering pulse nutritional quality. Finally, our results should be taken into account by food companies to propose pulse-based products displaying a sufficient micronutrient-density, as well as by Public Health Agency to promote pulse consumption in a wellbalanced diet rich in micronutrients.

This article is protected by copyright. All rights reserved. 


\section{Acknowledgement}

Authors declare no conflict of interest.

Authors are very grateful to Ndèye Y. Ba (C2VN, Marseille) for valuable technical help.

Marielle Margier received a doctoral fellowship (2015-2018) from Region PACA in partnership with the Centre Technique de Conservation des Produits Alimentaires (CTCPA Avignon).

This work was partly supported by an INRA Priority Action of the "Alimentation Humaine" department (2018-2020). The project leading to this publication has also received funding from Excellence Initiative of Aix-Marseille University - A*MIDEX, a French "Investissements d'Avenir" program.

This article is protected by copyright. All rights reserved. 


\section{References}

[1] Wiseman, E. M., Bar-El Dadon, S., Reifen, R., The vicious cycle of vitamin a deficiency: A review.

Crit Rev Food Sci Nutr 2017, 57, 3703-3714.

[2] Arabi, A., El Rassi, R., El-Hajj Fuleihan, G., Hypovitaminosis D in developing countries-prevalence, risk factors and outcomes. Nat Rev Endocrinol 2010, 6, 550-561.

[3] Dror, D. K., Allen, L. H., Vitamin E deficiency in developing countries. Food and nutrition bulletin 2011, 32, 124-143.

[4] McNinch, A., Vitamin K deficiency bleeding: early history and recent trends in the United Kingdom. Early Hum Dev 2010, 86 Suppl 1, 63-65.

[5] Hilger, J., Goerig, T., Weber, P., Hoeft, B., Eggersdorfer, M., Carvalho, N. C., Goldberger, U., Hoffmann, K., Micronutrient Intake in Healthy Toddlers: A Multinational Perspective. Nutrients 2015, 7, 6938-6955.

[6] Roman Vinas, B., Ribas Barba, L., Ngo, J., Gurinovic, M., Novakovic, R., Cavelaars, A., de Groot, L. C., van't Veer, P., Matthys, C., Serra Majem, L., Projected prevalence of inadequate nutrient intakes in Europe. Annals of nutrition \& metabolism 2011, 59, 84-95.

[7] Holick, M. F., The vitamin D deficiency pandemic: Approaches for diagnosis, treatment and prevention. Rev Endocr Metab Disord 2017, 18, 153-165.

[8] Azzi, A., Meydani, S. N., Meydani, M., Zingg, J. M., The rise, the fall and the renaissance of vitamin E. Arch Biochem Biophys 2016, 595, 100-108.

[9] Reboul, E., Absorption of vitamin A and carotenoids by the enterocyte: focus on transport proteins. Nutrients 2013, 5, 3563-3581.

This article is protected by copyright. All rights reserved. 
[10] Reboul, E., Intestinal absorption of vitamin D: from the meal to the enterocyte. Food Funct $2015,6,356-362$.

[11] Reboul, E., Vitamin E Bioavailability: Mechanisms of Intestinal Absorption in the Spotlight. Antioxidants (Basel) 2017, 6.

[12] Gan, Y., Hamel, C., O'Donovan, J. T., Cutforth, H., Zentner, R. P., Campbell, C. A., Niu, Y., Poppy, L., Diversifying crop rotations with pulses enhances system productivity. Sci Rep 2015, 5, 14625.

[13] Bouchenak, M., Lamri-Senhadji, M., Nutritional quality of legumes, and their role in cardiometabolic risk prevention: a review. J Med Food 2013, 16, 185-198.

[14] Anderson, J. W., Major, A. W., Pulses and lipaemia, short- and long-term effect: Potential in the prevention of cardiovascular disease. British Journal of Nutrition 2007, 88, 263-271.

[15] Asif, M., Rooney, L. W., Ali, R., Riaz, M. N., Application and opportunities of pulses in food system: a review. Crit Rev Food Sci Nutr 2013, 53, 1168-1179.

[16] Liu, N., Ru, Y., Wang, J., Xu, T., Effect of dietary sodium phytate and microbial phytase on the lipase activity and lipid metabolism of broiler chickens. Br J Nutr 2010, 103, 862-868.

[17] Han, L. K., Zheng, Y. N., Xu, B. J., Okuda, H., Kimura, Y., Saponins from platycodi radix ameliorate high fat diet-induced obesity in mice. J Nutr 2002, 132, 2241-2245.

[18] Zhao, H. L., Sim, J. S., Shim, S. H., Ha, Y. W., Kang, S. S., Kim, Y. S., Antiobese and hypolipidemic effects of platycodin saponins in diet-induced obese rats: evidences for lipase inhibition and calorie intake restriction. Int J Obes (Lond) 2005, 29, 983-990.

[19] Chavez-Santoscoy, R. A., Gutierrez-Uribe, J. A., Serna-Saldivar, S. O., Effect of flavonoids and saponins extracted from black bean (Phaseolus vulgaris L.) seed coats as cholesterol micelle disruptors. Plant foods for human nutrition 2013, 68, 416-423.

This article is protected by copyright. All rights reserved. 
[20] Margier, M., George, S., Hafnaoui, N., Remond, D., Nowicki, M., Du Chaffaut, L., Amiot, M. J., Reboul, E., Nutritional Composition and Bioactive Content of Legumes: Characterization of Pulses Frequently Consumed in France and Effect of the Cooking Method. Nutrients 2018, 10.

[21] Malapert, A., Tomao, V., Margier, M., Nowicki, M., Gleize, B., Dangles, O., Reboul, E., betaCyclodextrin Does not Alter the Bioaccessibility and the Uptake by Caco-2 Cells of Olive By-Product Phenolic Compounds. Nutrients 2018, 10.

[22] Reboul, E., Richelle, M., Perrot, E., Desmoulins-Malezet, C., Pirisi, V., Borel, P., Bioaccessibility of carotenoids and vitamin E from their main dietary sources. J Agric Food Chem 2006, 54, 8749-8755.

[23] Reboul, E., Abou, L., Mikail, C., Ghiringhelli, O., Andre, M., Portugal, H., Jourdheuil-Rahmani, D., Amiot, M. J., Lairon, D., Borel, P., Lutein transport by Caco-2 TC-7 cells occurs partly by a facilitated process involving the scavenger receptor class B type I (SR-BI). Biochem J 2005, 387, 455-461.

[24] Goncalves, A., Margier, M., Tagliaferri, C., Lebecque, P., George, S., Wittrant, Y., Coxam, V., Amiot, M. J., Reboul, E., Pinoresinol of olive oil decreases vitamin D intestinal absorption. Food Chem $2016,206,234-238$.

[25] Reboul, E., Goncalves, A., Comera, C., Bott, R., Nowicki, M., Landrier, J. F., Jourdheuil-Rahmani, D., Dufour, C., Collet, X., Borel, P., Vitamin D intestinal absorption is not a simple passive diffusion: evidences for involvement of cholesterol transporters. Mol Nutr Food Res 2011, 55, 691-702.

[26] Gleize, B., Steib, M., Andre, M., Reboul, E., Simple and fast HPLC method for simultaneous determination of retinol, tocopherols, coenzyme $\mathrm{Q}(10)$ and carotenoids in complex samples. Food Chem 2012, 134, 2560-2564.

[27] Sandberg, A. N., Bioavailability of minerals in legumes. British Journal of Nutrition 2002, 33, S281-285.

This article is protected by copyright. All rights reserved. 
[28] Marlett, J. A., Content and composition of dietary fiber in 117 frequently consumed foods. J Am Diet Assoc 1992, 92, 175-186.

[29] Vahouny, G. V., Tombes, R., Cassidy, M. M., Kritchevsky, D., Gallo, L. L., Dietary fibers: V. Binding of bile salts, phospholipids and cholesterol from mixed micelles by bile acid sequestrants and dietary fibers. Lipids 1980, 15, 1012-1018.

[30] Riedl, J., Linseisen, J., Hoffmann, J., Wolfram, G., Some dietary fibers reduce the absorption of carotenoids in women. J Nutr 1999, 129, 2170-2176.

[31] Kies, A. K., De Jonge, L. H., Kemme, P. A., Jongbloed, A. W., Interaction between protein, phytate, and microbial phytase. In vitro studies. J Agric Food Chem 2006, 54, 1753-1758.

[32] Gu, Y., Hurst, W. J., Stuart, D. A., Lambert, J. D., Inhibition of key digestive enzymes by cocoa extracts and procyanidins. J Agric Food Chem 2011, 59, 5305-5311.

[33] Oliveira, R. F., Goncalves, G. A., Inacio, F. D., Koehnlein, E. A., de Souza, C. G., Bracht, A., Peralta, R. M., Inhibition of Pancreatic Lipase and Triacylglycerol Intestinal Absorption by a Pinhao Coat (Araucaria angustifolia) Extract Rich in Condensed Tannin. Nutrients 2015, 7, 5601-5614.

[34] Desmarchelier, C., Margier, M., Preveraud, D. P., Nowicki, M., Rosilio, V., Borel, P., Reboul, E., Comparison of the Micellar Incorporation and the Intestinal Cell Uptake of Cholecalciferol, 25Hydroxycholecalciferol and 1-alpha-Hydroxycholecalciferol. Nutrients 2017, 9.

[35] Goncalves, A., Margier, M., Roi, S., Collet, X., Niot, I., Goupy, P., Caris-Veyrat, C., Reboul, E., Intestinal scavenger receptors are involved in vitamin K1 absorption. J Biol Chem 2014, 289, 3074330752.

[36] Borel, P., Lietz, G., Goncalves, A., Szabo de Edelenyi, F., Lecompte, S., Curtis, P., Goumidi, L., Caslake, M. J., Miles, E. A., Packard, C., Calder, P. C., Mathers, J. C., Minihane, A. M., Tourniaire, F., Kesse-Guyot, E., Galan, P., Hercberg, S., Breidenassel, C., Gonzalez Gross, M., Moussa, M., 
Meirhaeghe, A., Reboul, E., CD36 and SR-BI Are Involved in Cellular Uptake of Provitamin A

Carotenoids by Caco-2 and HEK Cells, and Some of Their Genetic Variants Are Associated with

Plasma Concentrations of These Micronutrients in Humans. J Nutr 2013, 143, 448-456.

[37] Reboul, E., Trompier, D., Moussa, M., Klein, A., Landrier, J. F., Chimini, G., Borel, P., ATP-binding cassette transporter A1 is significantly involved in the intestinal absorption of alpha- and gammatocopherol but not in that of retinyl palmitate in mice. Am J Clin Nutr 2009, 89, 177-184.

[38] Goncalves, A., Gleize, B., Roi, S., Nowicki, M., Dhaussy, A., Huertas, A., Amiot, M. J., Reboul, E., Fatty acids affect micellar properties and modulate vitamin D uptake and basolateral efflux in Caco-2 cells. J Nutr Biochem 2013, 24, 1751-1757.

[39] Goncalves, A., Gontero, B., Nowicki, M., Margier, M., Masset, G., Amiot, M. J., Reboul, E., Micellar lipid composition affects micelle interaction with class B scavenger receptor extracellular loops. J Lipid Res 2015, 56, 1123-1133.

[40] Jenkins, K. J., Atwal, A. S., Effects of dietary saponins on fecal bile acids and neutral sterols, and availability of vitamins A and $E$ in the chick. The Journal of Nutritional Biochemistry 1994, 5, 134-137. [41] Johnson, I. T., Gee, J. M., Price, K., Curl, C., Fenwick, G. R., Influence of saponins on gut permeability and active nutrient transport in vitro. J Nutr 1986, 116, 2270-2277.

[42] Reboul, E., Thap, S., Perrot, E., Amiot, M. J., Lairon, D., Borel, P., Effect of the main dietary antioxidants (carotenoids, gamma-tocopherol, polyphenols, and vitamin C) on alpha-tocopherol absorption. Eur J Clin Nutr 2007.

[43] Reboul, E., Thap, S., Tourniaire, F., Andre, M., Juhel, C., Morange, S., Amiot, M. J., Lairon, D., Borel, P., Differential effect of dietary antioxidant classes (carotenoids, polyphenols, vitamins $\mathrm{C}$ and E) on lutein absorption. Br J Nutr 2007, 97, 440-446.

This article is protected by copyright. All rights reserved. 
[44] Miura, S., Saku, K., Ezetimibe, a selective inhibitor of the transport of cholesterol. Intern Med $2008,47,1165-1170$.

[45] Shen, W. J., Hu, J., Hu, Z., Kraemer, F. B., Azhar, S., Scavenger receptor class B type I (SR-BI): a versatile receptor with multiple functions and actions. Metabolism 2014, 63, 875-886.

[46] Bohn, T., Dietary factors affecting polyphenol bioavailability. Nutr Rev 2014, 72, 429-452.

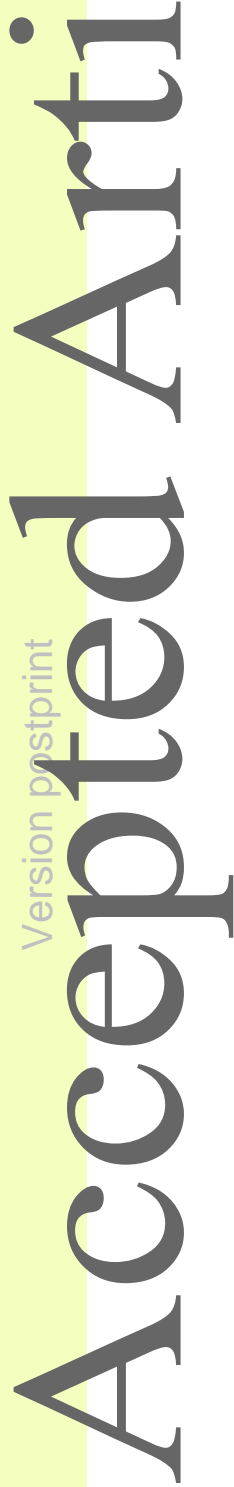

This article is protected by copyright. All rights reserved. 
Tables

Table 1: Household cooking method

\begin{tabular}{|c|c|c|}
\hline Pulses & Soaking in low ionized water* & Cooking time in mineral water $* *$ \\
\hline Kidney beans & \multirow{5}{*}{$\begin{array}{l}\text { Overnight at room temperature; } \\
\text { ratio seeds: water (w:w) of 1:5. }\end{array}$} & 1h30; ratio seeds: water (w:w) of 1:2. \\
\hline White beans & & 1h30; ratio seeds: water (w:w) of 1:2. \\
\hline Chickpeas & & $2 \mathrm{~h}$; ratio seeds: water (w:w) of $1: 2$ \\
\hline Green lentils & & 25 min; ratio seeds: water (w:w) of 1:2 \\
\hline Flageolets & & 1h30; ratio seeds: water (w:w) of 1:2. \\
\hline
\end{tabular}

* (water hardness: $\left.10-15^{\circ} \mathrm{F}\right),{ }^{* *}$ Pyrenea water (Auchan, Croix, France).

Table 2: Canning method

\begin{tabular}{|c|c|c|c|}
\hline Pulses & Soaking in low ionized water* & Blanching & Canning temperature \\
\hline Kidney beans & \multirow{4}{*}{$\begin{array}{l}\text { Overnight at room temperature; } \\
\text { ratio seeds: water (w:w) of 1:3. }\end{array}$} & \multirow{4}{*}{$\begin{array}{l}5 \mathrm{~min} \text { at } \\
90^{\circ} \mathrm{C}\end{array}$} & \multirow{4}{*}{$\begin{array}{l}16 \mathrm{~min} \text { at } 127^{\circ} \mathrm{C} \text {, then cooled } \\
\text { to } 30^{\circ} \mathrm{C} \text { for } 10 \mathrm{~min} \text { in brine } \\
(0.5 \% \text { salt); ratio seeds: brine } \\
\text { (w:w) of } 195: 236 .\end{array}$} \\
\hline White beans & & & \\
\hline Chickpeas & & & \\
\hline Brown lentils & & & \\
\hline
\end{tabular}

* (water hardness: $10-15^{\circ} \mathrm{F}$ )

This article is protected by copyright. All rights reserved. 
Table 3

\begin{tabular}{|c|c|c|c|c|c|c|c|c|c|c|}
\hline & \multicolumn{2}{|c|}{ Red beans } & \multicolumn{2}{|c|}{ White beans } & \multicolumn{2}{|c|}{ Chickpeas } & \multirow{2}{*}{$\begin{array}{c}\text { Green } \\
\text { lentils } \\
\text { Househol } \\
\text { d cooking }\end{array}$} & \multirow{2}{*}{$\begin{array}{l}\text { Brown } \\
\text { lentils } \\
\text { Canning }\end{array}$} & \multirow{2}{*}{$\begin{array}{l}\text { Flageolets } \\
\text { Household } \\
\text { cooking }\end{array}$} & \multirow{2}{*}{$\begin{array}{l}\text { Pureed } \\
\text { potatoes }\end{array}$} \\
\hline & $\begin{array}{l}\text { Househol } \\
\text { d cooking }\end{array}$ & Canning & $\begin{array}{l}\text { Househol } \\
\text { d cooking }\end{array}$ & Canning & $\begin{array}{l}\text { Househol } \\
d \text { cooking }\end{array}$ & Canning & & & & \\
\hline $\begin{array}{l}\text { Total dietary } \\
\text { fibers (g/100 g) }\end{array}$ & $11.6 \pm 2.5$ & $6.5 \pm 2.1^{*}$ & $10.0 \pm 2.4$ & $6.7 \pm 2.2$ & $8.2 \pm 2.3$ & $6.4 \pm 2.1$ & $8.5 \pm 2.3$ & $3.8 \pm 1.9$ & $13.8 \pm 2.7$ & $2.2 \pm 0.0$ \\
\hline & $627.3 \pm 42.4$ & $386.3 \pm 25.5^{*}$ & $532.4 \pm 28.3$ & $470.3 \pm 48.1$ & $693.9 \pm 40.7$ & $526.4 \pm 22.3^{*}$ & $714.5 \pm 28.9$ & $412.6 \pm 36.3$ & $683.7 \pm 65.7$ & $141.5 \pm 19.6$ \\
\hline & $106.0 \pm 4.1$ & $118.6 \pm 4.8$ & $104.0 \pm 5.7$ & $107.6 \pm 0.6$ & $121.9 \pm 4.7$ & $116.8 \pm 0.2^{*}$ & $174.7 \pm 2.7$ & $98.7 \pm 2.7$ & $122.1 \pm 2.3$ & $32.3 \pm 1.3$ \\
\hline & $6.8 \pm 0.4$ & $5.4 \pm 0.3^{*}$ & $1.7 \pm 0.0$ & $1.8 \pm 0.1$ & $16.6 \pm 1.9$ & $13.7 \pm 1.5$ & $12.5 \pm 0.2$ & $7.5 \pm 0.1$ & $2.2 \pm 0.1$ & n.d. \\
\hline polyphenols & $66.3 \pm 2.5$ & $67.1 \pm 2.5$ & $15.0 \pm 1.1$ & $18.7 \pm 1.374$ & $25.0 \pm 1.2$ & $27.6 \pm 1.3$ & $284.3 \pm 3.3$ & $71.8 \pm 0.8$ & $15.8 \pm 0.8$ & n.d. \\
\hline
\end{tabular}

Data are means $\pm \mathrm{SD}(n=3-4)$. An asterisk indicates a significant difference $(p<0.05)$

between the two cooking methods . n.d. = not detectable or below the limit of quantitation in the sample.

This article is protected by copyright. All rights reserved. 


\section{Figure legends}

Figure 1: Effect of pulses on fat-soluble vitamin bioaccessibility

In vitro digestion experiments were performed with test meals containing minced beef meat, refined olive oil supplemented with fat-soluble vitamins, and either potatoes (control condition, white bar), household cooked pulses (black bar) or canned pulses (striped bar). Vitamin bioaccessibility was calculated as the percentage of vitamin recovered in mixed micelles divided by the amount of vitamin recovered in the digesta at the end of the digestion. Data are means \pm SEM $(n=4$ per condition). Means values followed by a different superscript letter are significantly different $(p<$ $0.05)$.
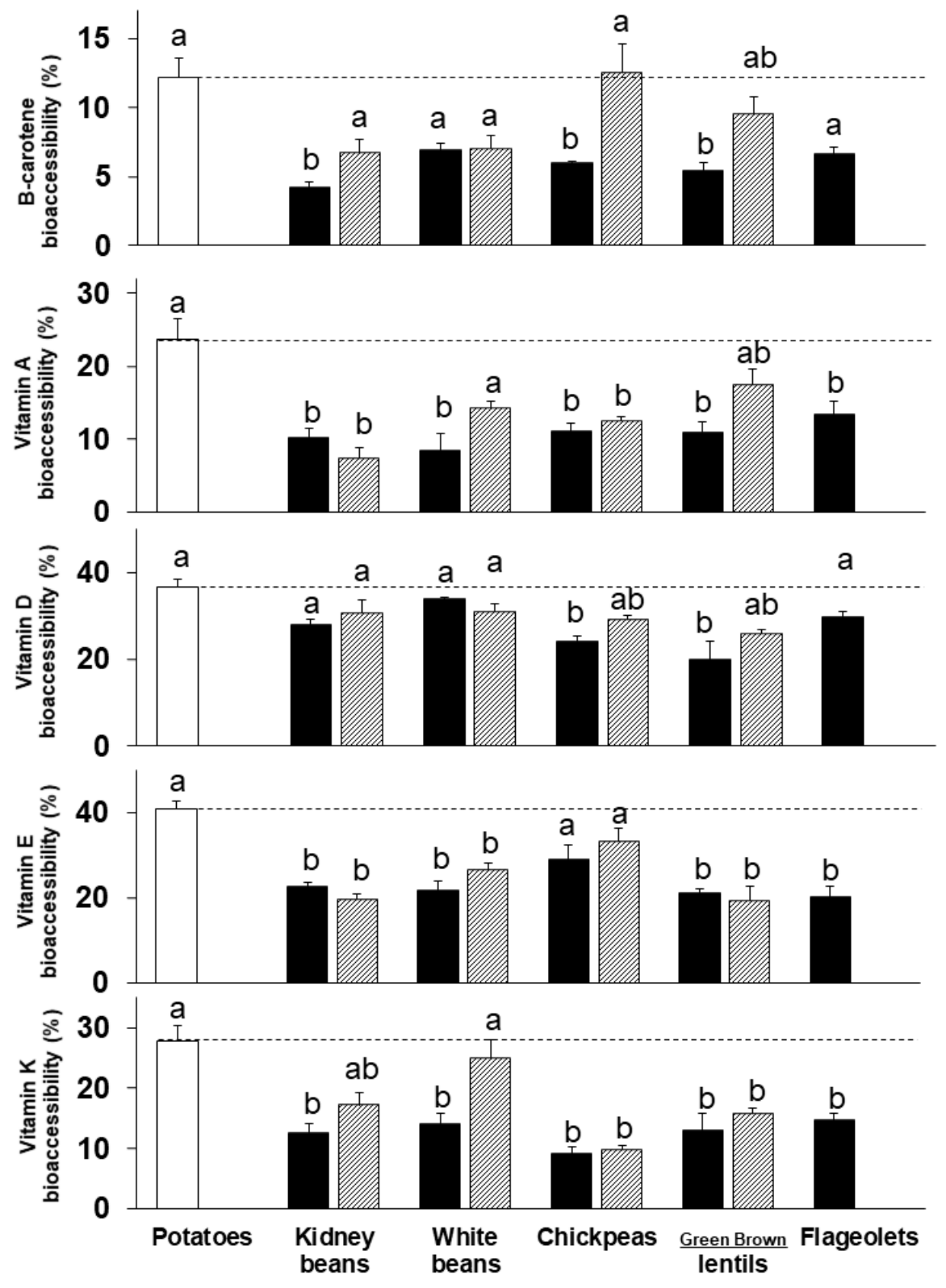

This article is protected by copyright. All rights reserved.

Comment citer ce document 
Figure 2: Effect of pulses on fat-soluble vitamin uptake by Caco-2 cells

At the beginning of the experiment, the apical side received fat-soluble vitamin-rich micelles obtained from in vitro digestions of meal containing either potatoes (white bar), household cooked pulses (black bar) or canned pulses (striped bar) at a 1:7 dilution. Cells were then incubated $1 \mathrm{~h}$ at $37^{\circ} \mathrm{C}$. Absorbed vitamin was calculated as the percentage of the amount of vitamin recovered in cells divided by the total amount of vitamin delivered to the cells (i.e vitamin found in the medium plus vitamin remaining in the cells at the end of the experiment). Data are means \pm SEM ( $n=4$ per condition). Means values followed by a different superscript letter are significantly different $(p<$ 0.05).
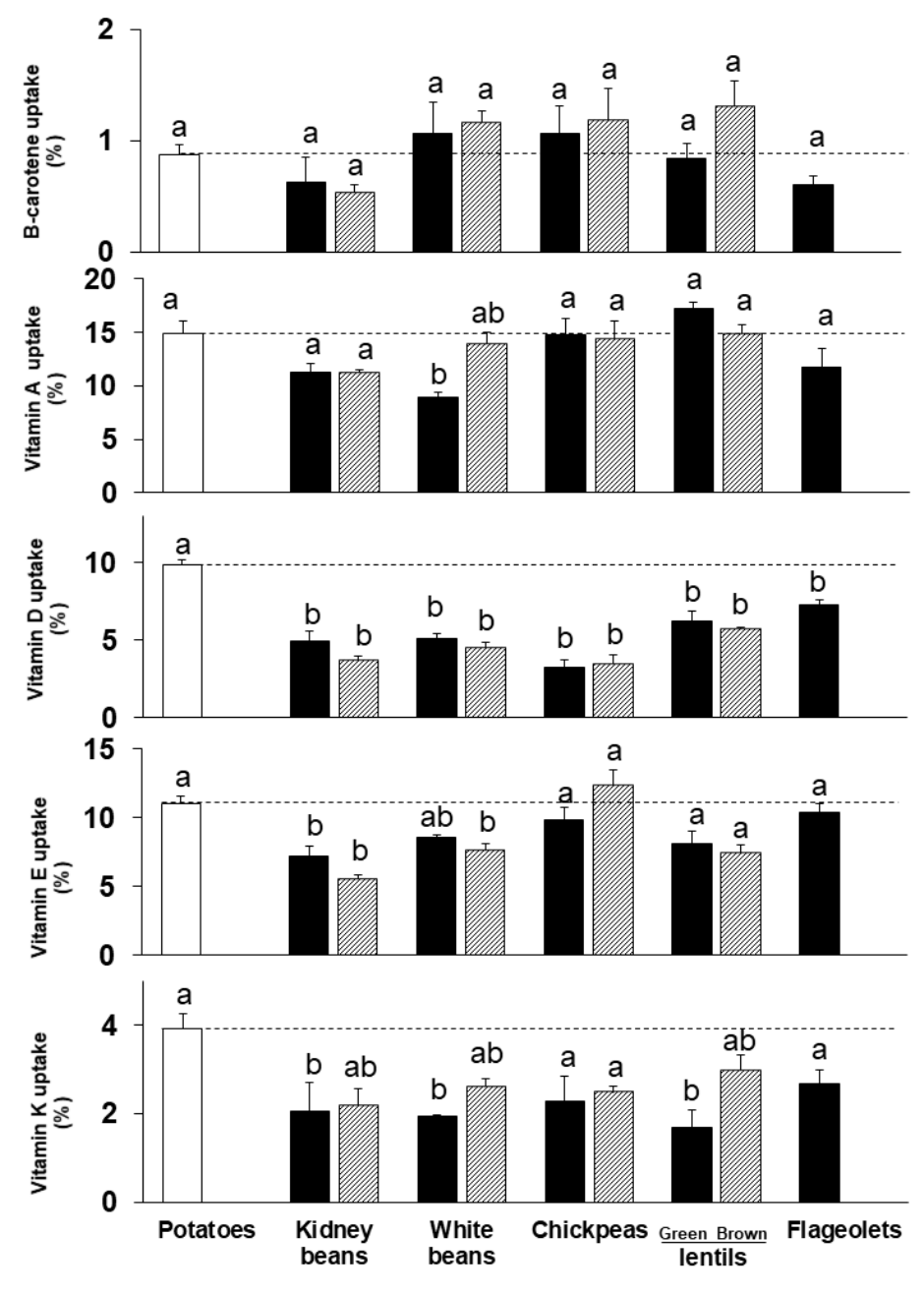

This article is protected by copyright. All rights reserved. 
Figure 3 : Relashionship between fat-soluble vitamin bioaccessiblity/ uptake and meal content in phytates, saponins ans tannins.

A principal Component Analysis (PCA) was conducted on all samples (potatoes (x), householdcooked kidney beans (o), canned kidney beans $(\bullet)$, household cooked white beans $(\square)$, canned white beans $(\boldsymbol{\square})$, household cooked chichpeas $(\Delta)$, canned chickpeas $(\boldsymbol{\Delta})$, household cooked green lentils $(\diamond)$, canned brown lentils $(\diamond)$, household cooked flageolets $(+)$, upper panel) to analyze the relationship between the presence of fibers, phytates, saponins, tannins (dotted arrows, lower panel) and fat-soluble vitamin bioaccessibility (dashed arrows) and uptake (thick arrows).

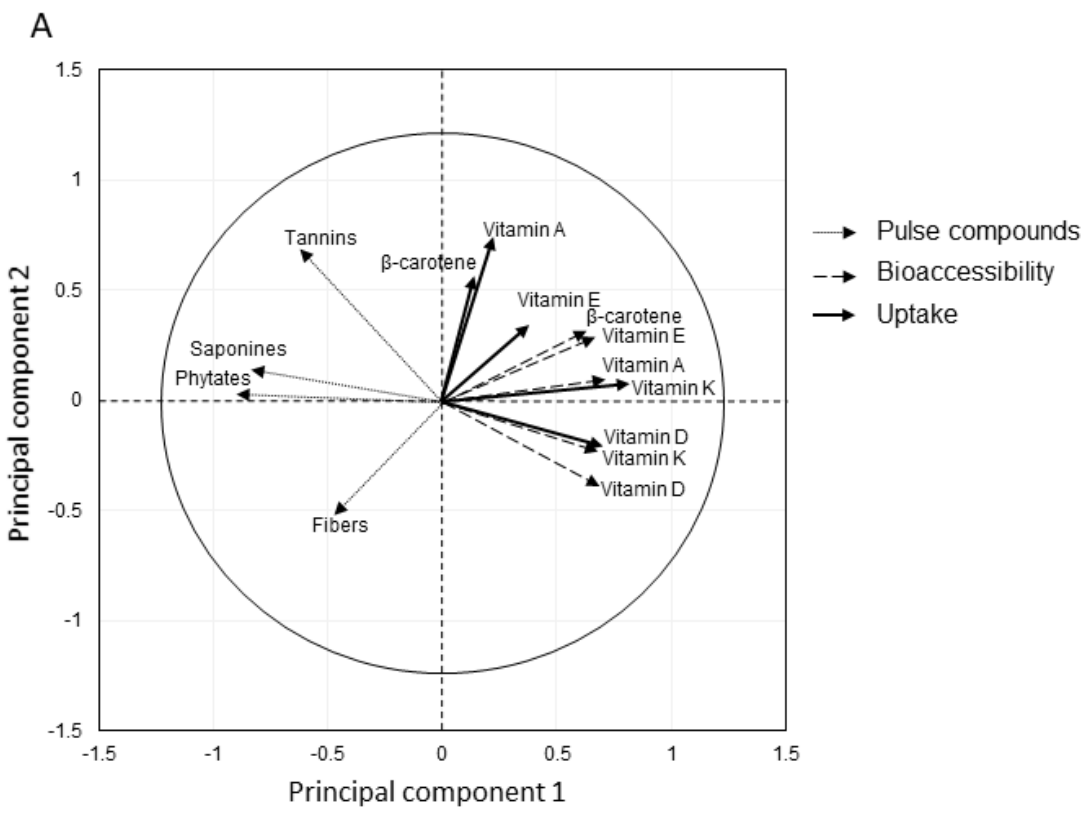

B

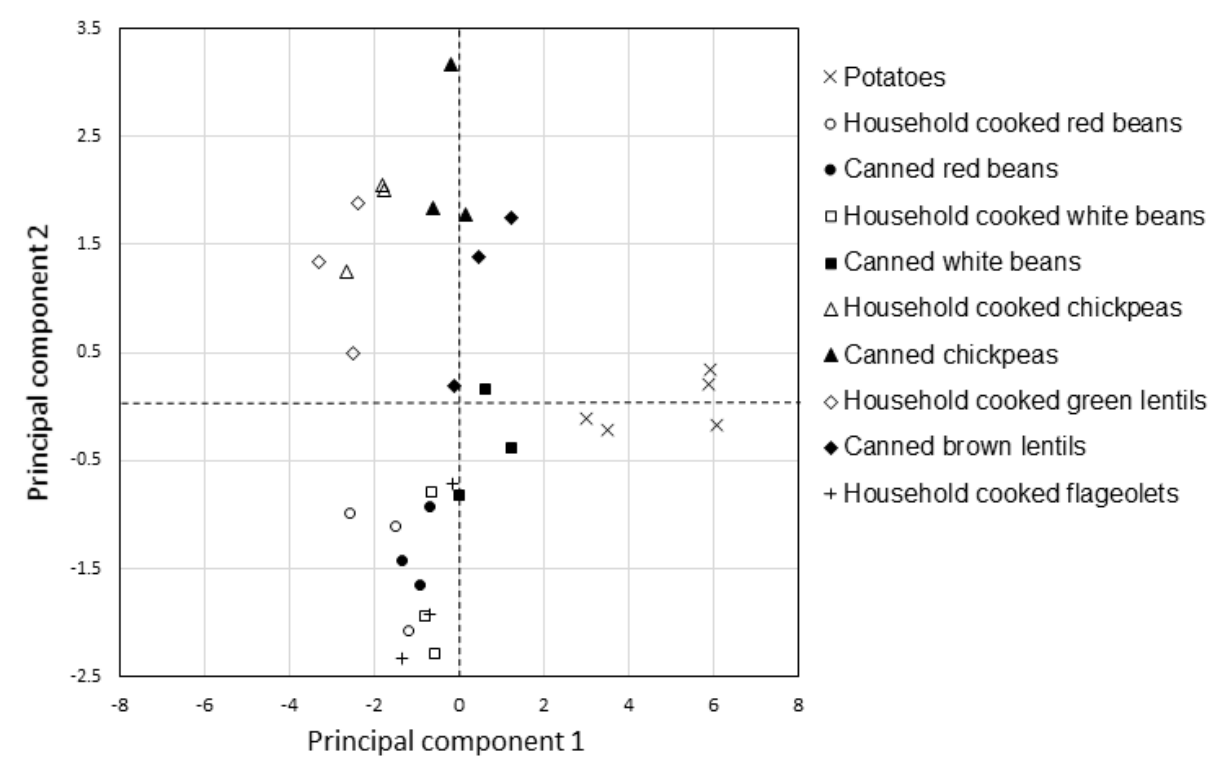

This article is protected by copyright. All rights reserved. 
Figure 4 : Effect of specific pulse compounds on vitamin $\mathrm{K}$ bioaccessibility.

In vitro digestion experiments were performed with test meals containing minced beef meat, refined olive oil supplemented with vitamin $\mathrm{K}$, potatoes, and enriched in purified cellulose $(0.7 \mathrm{mg})$, phytates (42.5 mg), saponins ( $6 \mathrm{mg}$ ) and tannins $(0.4 \mathrm{mg}$ ). Vitamin $\mathrm{K}$ bioaccessibility was calculated as the percentage of vitamin recovered in mixed micelles divided by the amount of vitamin recovered in the digesta at the end of the digestion. Data are means \pm SEM ( $n=4$ per condition). ${ }^{*} p<0.05,{ }^{* *}$ $p<0.01, * * p<0.001$ when compared with control.

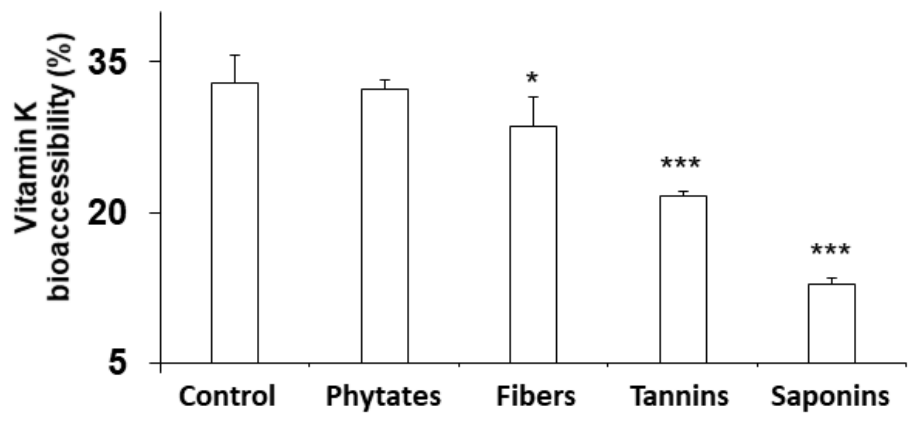

This article is protected by copyright. All rights reserved. 
